\title{
Correction to: Motion analysis for better understanding of psychomotor skills in laparoscopy: objective assessment-based simulation training using animal organs
}

\author{
Koki Ebina ${ }^{2}$ - Takashige Abe ${ }^{1}$ - Madoka Higuchi ${ }^{1}$. Jun Furumido ${ }^{1}$ - Naoya Iwahara ${ }^{1} \cdot$ Masafumi Kon $^{1}$. \\ Kiyohiko Hotta ${ }^{1}$. Shunsuke Komizunai ${ }^{2}$. Yo Kurashima ${ }^{3}$ - Hiroshi Kikuchi ${ }^{1}$. Ryuji Matsumoto ${ }^{1}$ - Takahiro Osawa ${ }^{1}$. \\ Sachiyo Murai ${ }^{1} \cdot$ Teppei Tsujita $^{4} \cdot$ Kazuya Sase $^{5} \cdot$ Xiaoshuai Chen $^{6}$ - Atsushi Konno ${ }^{2} \cdot$ Nobuo Shinohara $^{1}$
}

(c) The Author(s) 2020

\section{Correction to: Surgical Endoscopy https://doi.org/10.1007/s00464-020-07940-7}

This article was updated to correct the labeling of Fig. 6.

Open Access This article is licensed under a Creative Commons Attribution 4.0 International License, which permits use, sharing, adaptation, distribution and reproduction in any medium or format, as long as you give appropriate credit to the original author(s) and the source, provide a link to the Creative Commons licence, and indicate if changes were made. The images or other third party material in this article are included in the article's Creative Commons licence, unless indicated otherwise in a credit line to the material. If material is not included in the article's Creative Commons licence and your intended use is not permitted by statutory regulation or exceeds the permitted use, you will need to obtain permission directly from the copyright holder. To view a copy of this licence, visit http://creativecommons.org/licenses/by/4.0/.

Publisher's Note Springer Nature remains neutral with regard to jurisdictional claims in published maps and institutional affiliations.

Koki Ebina and Takashige Abe have contributed equally to this work.

The original article can be found online at https://doi.org/10.1007/ s00464-020-07940-7.

Takashige Abe

takataka@rf6.so-net.ne.jp

1 Department of Urology, Hokkaido University Graduate School of Medicine, North-15, West-7, North Ward, Sapporo 060-8638, Japan

2 Graduate School of Information Science and Technology, Hokkaido University, Sapporo, Japan

3 Hokkaido University Clinical Simulation Center, Hokkaido University Graduate School of Medicine, Sapporo, Japan

4 Department of Mechanical Engineering, National Defense Academy, Yokosuka 239-8686, Japan

5 Department of Mechanical Engineering and Intelligent Systems, Tohoku Gakuin University, Tagajo 985-8537, Japan

6 Graduate School of Science and Technology, Hirosaki University, Hirosaki 036-8561, Japan 